\title{
ESTUDO SOBRE OS CURSOS FERROVIÁRIOS NOS ANOS DE 1940 A 1960 A PARTIR DE REVISTAS FERROVIÁRIAS
}

\author{
Sueli Soares dos Santos Batista" \\ Centro Paula Souza (CPS) \\ Maria Lúcia Mendes de Carvalho** \\ Centro Paula Souza (CPS)
}

RESUMO: Ao serem estudadas a concepção, a implantação e a extinção dos cursos ferroviários na educação profissional em São Paulo entre o início do século XX e os anos de 1960, encontra-se uma série de lacunas na historiografia e mesmo na documentação. Percebe-se que esses cursos trouxeram uma nova experiência para a formação do operariado, pois eram administrados e financiados por setores industriais e estatais, passando a capacitação profissional a ser não apenas de responsabilidade privada, mas, também, a receber apoio do poder público. Este artigo, além de pesquisa bibliográfica, apresenta leitura e análise da legislação e de artigos publicados pela Revista Nossa Estrada e a Revista Ferroviária sobre o tema. Assim, apresenta-se contribuição para os estudos sobre a formação do trabalhador ferroviário nas estradas de ferro a partir da extinção do CFESP, mostrando a importância das revistas ferroviárias para a compreensão desse processo nos anos de 1940 a 1960.

Palavras-chave: História da educação profissional. Revistas ferroviárias. Patrimônio industrial e educativo.

http://dx.doi.org/10.1590/0102-4698120457

* Doutora em Psicologia da Aprendizagem e do Desenvolvimento Humano pela Universidade de São Paulo. Professora pesquisadora do Centro Paula Souza, atuando no Mestrado Profissional em Educação Profissional e coordenando o Núcleo de Estudos de Tecnologia e Sociedade (NETS). E-mail: suelissbatista@uol.com.br.

* * Doutora em Planejamento e Desenvolvimento Rural Sustentável na Faculdade de Engenharia Agrícola da Universidade Estadual de Campinas. Professora coordenadora de projetos no Centro Paula Souza, professora colaboradora do Mestrado Profissional e coordenadora do Grupo de Estudos e Pesquisas em Memórias e História da Educação Profissional (GEPEMHEP) da mesma instituição. E-mail: marialuciamcarvalho@hotmail.com. 


\section{STUDY ABOUT RAILWAY COURSES BETWEEN 1940 TO 1960 FROM RAILWAY MAGAZINES}

ABSTRACT: A series of blanks in the historiography and even documentation were found while studying the conception, implementation and extinction of the railway-related courses on professional education in São Paulo from the beginning of the 20th century until the years of 1960. It is noticeable that these courses brought a new experience to the education of the laborers, since they were managed and funded by industrial and state departments. The professional capacitation was no longer a private initiative's sole responsibility, receiving support from the government. This article, beyond bibliographical research, presents reading and analysis of the legislation and articles published by "Revista Nossa Estada" and "Revista Ferroviária" about the subject. The article presents contributions to the studies about the formation of railway workers about railways since the extinction of CFESP, showing the importance of the railway-related periodicals for the comprehension of this process on the years 1940 to 1960.

Keywords: History of Professional Education. Railway Periodicals. Industrial and Educational Heritage.

\section{INTRODUÇÃO}

Por ocasião do Fórum Mundial de Educação Profissional e Tecnológica, ocorrido em Brasília - DF, em novembro de 2009, os estudos sobre educação para o trabalho na era ferroviária que resultaram neste artigo estavam se iniciando. A revisão bibliográfica e o contato com a historiografia específica sobre o assunto proporcionaram o conhecimento de alguns aspectos aqui retomados.

Este estudo se insere, numa perspectiva ampla, como uma tentativa de compreender propostas educacionais no contexto das relações de trabalho e de produção que se legitimam na história da educação profissional no Brasil como fundamentais para o desenvolvimento econômico. A relação entre trabalho, educação e desenvolvimento é carente de estudos e análises que possam dissipar, conforme afirma Segnini (2000, p. 15), algo que parece ser "uma névoa que encobre essa relação" impossibilitando que se perceba de maneira mais efetiva "os elementos que constroem o consenso, no interior de conflitos e interesses antagônicos" (SEGNINI, 2000, p. 15).

A presente pesquisa se desenvolveu no contexto do Projeto Memória Ferroviária, com a participação de alunos e docentes da Faculdade de Tecnologia de Jundiaí e da unidade de Rosana da Universidade Estadual Paulista (UNESP), ambas as cidades localizadas no interior de São Paulo. O objetivo geral desse projeto 
foi efetuar um levantamento da documentação de ferrovias e do inventário de conjuntos de patrimônio industrial no interior do estado de São Paulo, entre 1868 e 1971. O estudo, iniciado em 2008, esteve centrado nas principais ferrovias e companhias que operaram no estado em meados do século XIX ao século XX, como: Estrada de Ferro Sorocabana, Estrada de Ferro Araraquara, Estrada de Ferro São Paulo-Minas e Noroeste do Brasil, Companhia Mogiana e Companhia Paulista de Estradas de Ferro'. O Projeto Memória Ferroviária vai ao encontro do esforço de conhecer, catalogar e digitalizar o acervo das companhias férreas do estado de São Paulo, do qual só recentemente se tem a dimensão da documentação produzida: 14 mil fotografias, 4 mil mapas e desenhos técnicos, 900 caixas de documentação e periódicos e mais de 13 mil livros que estão nos acervos do Museu da Companhia Paulista, em Jundiaí, no Arquivo do Estado, em São Paulo, e no Centro de Memória da Rede Ferroviária Federal S/A (RFFSA), em Bauru.

O espaço físico destinado anteriormente à Companhia Paulista de Estradas de Ferro, em Jundiaí, recebeu o nome de Complexo FEPASA, por ocorrer nos anos de 1970 a estatização dessa companhia, que passou a fazer parte da empresa Ferrovias Paulistas S/A (FEPASA). Esse complexo, em seus diferentes galpões, abriga algumas repartições públicas atualmente. Entre elas estão a Faculdade de Tecnologia de Jundiaí, instituição pública de ensino vinculada ao Centro Estadual de Educação Tecnológica Paula Souza, e o Museu da Companhia Paulista, que conta com uma biblioteca, além de sediar o Conselho do Patrimônio Cultural e da Diretoria de Patrimônio Cultural de Jundiaí.

Além de objetos museológicos e do próprio espaço arquitetônico tombado pelo Instituto do Patrimônio Histórico e Artístico Nacional (IPHAN) desde 2002, o acervo da Companhia Paulista no chamado Complexo FEPASA, em Jundiaí, conta com documentos manuscritos, bibliográficos, iconográficos e cartográficos. Somente nos anos de 1990 é que o museu passaria por um processo de reorganização de seu acervo ferroviário e por reforma predial. Parte do acervo foi, então, redistribuído para as suas cidades originais, como: Campinas, Araraquara e Sorocaba (MUSEU DA COMPANHIA PAULISTA, 2012).

O contato com a documentação relativa ao Centro Ferroviário de Ensino e Seleção Profissional (CFESP), existente na biblioteca do Museu da Companhia Paulista em Jundiaí, proporcionou a constatação da proximidade da história da formação do trabalhador 
ferroviário com a formação da classe operária em São Paulo, com a história do Instituto de Organização Racional do Trabalho (IDORT) e com as parcerias entre a educação pública e as companhias férreas.

Essa constatação proporcionou uma aproximação com as pesquisas realizadas pelos docentes vinculados ao Grupo de Memórias e História da Educação Profissional (GEPEMHEP), a partir de 2010 (CARVALHO; BATISTA, 2012). O presente trabalho se insere no eixo temático "Cultura, saberes e práticas escolares e pedagógicas na educação profissional e tecnológica: arquivos escolares, bibliotecas e centros de documentação", que tem se desenvolvido no contexto das atividades desse grupo (GEPEMHEP, 2015).

OGEPEMHEPempreendeuumimportante esforçodepesquisa, cujos resultados foram apresentados no simpósio comemorativo dos 100 anos da educação profissional pública em São Paulo. Foi proposto aos docentes vinculados ao grupo o projeto de pesquisa "História oral sobre as ferrovias em São Paulo: ações e transformações na educação profissional de 1930 a 2010", com a finalidade de desvendar a origem e o processo de implementação e de evolução dos cursos ferroviários na educação profissional pública no estado de São Paulo.

O enfoque dessa pesquisa foram as experiências ocorridas nas companhias férreas a partir do final do século XIX quanto à formação de seus trabalhadores. As fontes bibliográficas referem-se à literatura já existente sobre educação profissional, especialmente, sobre as escolas de aprendizes ferroviários (CUNHA, 2005; FRIGOTTO; CIAVATTA; RAMOS, 2005; BOSCHETTI, 2006; CIAVATTA, 2009) e sobre o acervo da biblioteca do Museu da Companhia Paulista (ou Museus dos Ferroviários, em Jundiaî).

Considerando a relevância dos trabalhos de Zucchi (2004) e Salvadori (2006), sobre o problema de pesquisa ora esboçado, e as pesquisas de Boschetti, Macedo e Amaro (2006), especificamente sobre a experiência de Sorocaba no começo da República, ainda sob os auspícios da "era ferroviária", partiu-se do pressuposto de que a pesquisa pudesse resultar em significativa contribuição para o estudo do ensino profissional e tecnológico na sua relação com o desenvolvimento econômico e social da época.

Assim, este trabalho procura apresentar uma trajetória de pesquisa sobre a educação profissional com uma perspectiva não limitada à historiografia já tradicional sobre o tema. Destacando-se a historiografia existente sobre o assunto e a utilização de fontes históricas não necessariamente convencionais, como relatos orais e revistas ferroviárias, registra-se um esforço em compreender o 
contexto histórico da educação profissional desde o final do século XIX até o período compreendido entre os anos de 1940 e 1960, revelando que, em nossas pesquisas, iniciadas em 2009, chegou-se a um momento de síntese e balanço para encetar novos caminhos de pesquisa a partir de novas questões e para permanecer com algumas questões inicialmente formuladas.

O presente estudo tem como centro de toda problematização a experiência do CFESP, núcleo agregador de experiências surgidas no final do século XIX, que se propagou enquanto referencial de formação para o trabalho durante a Era Vargas e também no período subsequente.

Para esses estudos foi de fundamental importância a leitura, a análise e a confrontação dos inúmeros decretos eleis que regulamentaram a educação profissional pública, seja explicitando suas parcerias com o setor privado, seja criando um sistema próprio em decorrência das demandas surgidas com o Serviço Nacional de Aprendizagem Industrial (SENAI) e o decreto-lei federal n. 4984 de 1942. No entanto, o conhecimento da legislação nem sempre nos permite compreender as continuidades e rupturas em denominações e mesmo de permanência ou extinção de cursos, de instituições e de programas, sejam privados, sejam públicos, ou como resultado de parcerias público-privadas.

No que diz respeito à análise documental, em pesquisas mais recentes houve a oportunidade de aprofundá-las no acervo do museu da Companhia Paulista, em Jundiaí, para o estudo da cultura do trabalho existente nas ferrovias, no sentido de compreender as concepções e as práticas relativas à formação do trabalhador ferroviário. Este artigo, especificamente, apresenta dados publicados nas Revistas Nossa Estrada e Revista Ferroviária quanto à formação do trabalhador ferroviário entre os anos de 1940 e 1960. Antes de chegarmos a esse momento da pesquisa, é necessário explicitar nossos caminhos de análise, as fontes e a abordagem utilizadas, que nos permitiram compreender aspectos da história da educação profissional.

Assim, são apresentados, inicialmente, os resultados de estudos a partir de bibliografia específica no item dedicado ao histórico do ensino ferroviário em São Paulo do século XIX até meados dos anos de 1950. Para compreender e até mesmo ampliar o que essa bibliografia apresenta, as informações são confrontadas com relatórios da Companhia Paulista e com a legislação estadual e federal relativa ao ensino profissional e ferroviário. Esses estudos se mostraram fundamentais para que pudéssemos ao final deste artigo apresentar a leitura, a seleção e a análise de artigos publicados em revistas ferroviárias entre os anos de 1940 e 1960. 


\section{HISTÓRICO DO ENSINO FERROVIÁRIO EM SÃO PAULO: DO SÉCULO XIX ATÉ OS ANOS DE 1930 E 1940}

A partir de 1856 intensifica-se a valorização da formação de mão de obra qualificada através da instalação dos liceus de artes e ofícios. Os liceus espalhados nos estados do Rio de Janeiro, de São Paulo, do Paraná, de Santa Catarina, do Rio Grande do Sul, de Goiás e do Mato Grosso serão as primeiras instituições para o ensino profissionalizante, sendo acompanhados posteriormente por escolas profissionais, institutos técnicos e cursos ferroviários (FONSECA, 1986).

Enquanto imperativo para o desenvolvimento global da sociedade, a educação profissional e tecnológica conheceu iniciativas em todo o país antes mesmo de ser uma estratégia governamental de desenvolvimento nacional e local em parceria com o setor privado. Segundo Cunha (2005), desde o início do século XX, as empresas ferroviárias mantinham escolas para formação de seus operários e acusa a primeira delas como a Escola Prática de Aprendizes das Oficinas, fundada em 1906, no Rio de Janeiro.

No entanto, os relatórios da Companhia Paulista revelam que desde 1895 já existiam iniciativas para a formação profissional dos ferroviários. Os aprendizes já estavam lá desde 1895, aprendendo e trabalhando nas oficinas, misturados aos adultos. Mas, a escola efetivamente só seria fundada em 1901 (BATISTA, 2011).

Nesse período, havia a necessidade de um curso preliminar para os interessados, já que estes chegavam, em sua maioria, sem saber ler, nem escrever e não dominavam as quatro operações fundamentais. Campos (2013), estudando os relatórios da Companhia Mogiana e da Companhia Paulista produzidos no final do século XIX, constatou que, além da montagem do equipamento, estrangeiros foram contratados pelas companhias para exercerem cargos de chefia das oficinas, para a Inspetoria Geral, Chefia do Tráfego e Contadoria, para Chefia de Tração e Engenharia, cabendo à chefia das oficinas a Thomaz Hall. Segundo a autora,

[...] os funcionários estrangeiros foram os elementos que propiciaram este contato e conhecimento com as técnicas e tecnologias ferroviárias aos brasileiros, ainda pouco familiarizados com o universo ferroviário. Logo, o conhecimento das lides deste complexo maquinário foi passado aos aprendizes brasileiros pelos chefes e mecânicos estrangeiros e em atuação nestas companhias. (CAMPOS, 2013, p. 6)

A influência de trabalhadores estrangeiros não trouxe apenas aprimoramento técnico e transferência de tecnologia para as oficinas ferroviárias. Unido a esse processo de desenvolvimento industrial, 
tem-se o desenvolvimento de uma consciência de classe a ser controlada por setores empresariais e políticos dominantes. Esse tipo de formação foi negligenciado e diminuído na sua importância pela historiografia porque não atendia aos imperativos do desenvolvimento tecnológico e não explicitava as contradições sociais.

Segundo Medeiros (1987) essa aprendizagem anterior aos métodos de racionalização da formação e da cultura do trabalho consistia em

[...] admissão de um jovem menor de idade como praticante ou como aprendiz de baixa classe, selecionado por recomendação ou por outro motivo estranho à eventual capacidade do candidato. $\mathrm{O}$ preparo deste jovem processava-se em geral sem o necessário aperfeiçoamento cultural e técnico-teórico, dependendo de uma improvisação técnico-didática dos mestres de oficina, de boa ou má vontade de oficiais e da aquisição de vícios e defeitos. A formação integral do artífice decorrente de um processo evolutivo, era prejudicada pela utilização industrial intensiva e permanente assim como da capacidade produtiva porventura já adquirida pelo aprendiz. (MEDEIROS, 1987, p. 114)

Pode-se afirmar, portanto, que havia uma baixa produtividade desse aprendiz assim formado sem critérios de seleção e avaliação. No entanto, pode-se considerar que essas primeiras iniciativas já eram no sentido de formar uma classe operária, minimamente eficiente e pacífica do ponto de vista dos movimentos sociais grevistas já bastante comuns no começo do século XX, sendo os ferroviários os protagonistas desse processo. O que se percebe pelos relatórios da Companhia Paulista é que esse tipo de oficina-escola, apesar de suas limitações técnicas, devido à necessidade crescente de mão de obra alfabetizada e disciplinada, será o embrião para os Centros Ferroviários de Educação e Seleção Profissional (CFESP) implantados a partir de 1934. O CFESP se destacou pelo aprimoramento técnico e pelo controle social de seus aprendizes, sob os auspícios de uma nova mentalidade protagonizada inicialmente pelo Instituto de Organização Racional do Trabalho (IDORT) surgido em 1931.

A semente do Centro lançada em Sorocaba foi espalhada pelas cidades de Jundiaí, Rio Claro, Campinas, Araraquara, Bauru e Pindamonhangaba. Sob uma constante vigilância que objetivava a construção de uma consciência dos deveres para com a empresa, a família e a nação formaram-se os aprendizes chamados "racionais" em detrimento dos chamados "comuns" (FONSECA, 1986).

Para Camoleze (2012), nas ferrovias paulistas a formação de uma consciência cooperativista dos ferroviários, em detrimento de uma consciência de classe que buscasse a transformação das condições de trabalho e de vida, se fez por meio das iniciativas do CFESP. 
O autor chega a essa conclusão a partir da leitura e análise de escritos de Roberto Mange. Esse educador afirmava que essa formação, a qual o jovem se destinava nas unidades do CFESP, não se limitava apenas à consciência técnica, mas a uma postura política e de ética profissional em relação à organização dos processos de trabalho. O objetivo era apurar as habilidades dos trabalhadores de tal forma que pudessem identificar problemas técnicos de maneira integral: através de seu corpo e de sua consciência, conforme Mange declarou no Congresso de Engenharia e Legislação Ferroviária realizado em Campinas em 1935 (CAMOLEZE, 2012).

Ainda pouco estudado, o CFESP, de todo modo, insere-se na lógica do processo brasileiro de industrialização em que a preparação da mão de obra, segundo Rangel (2009),

[...] não necessitou superar as corporações de ofício e seus instrumentos de unidade e mobilização, mas tratou-se de adaptar, com máxima urgência, um trabalhador - que até então era valorizado essencialmente por suas condições de saúde e força física - para os novos parâmetros operacionais, trazidos com as máquinas europeias e norte-americanas. (RANGEL, 2009, p. 3)

Era uma nova formação para o trabalho em que se produziam trabalhadores "racionais" em detrimento dos trabalhadores "comuns". Essa formação, segundo Bryan (2008) exigia:

[...] um conjunto de dispositivos de controle do processo de ensino somente aplicáveis, eficientemente, com a criação de um espaço e tempo de aprendizagem à margem da produção, em que a autoridade do artífice, adveniente da posse do saber tradicional, foi substituída pela autoridade impessoal das regras emanadas da organização racional do trabalho. (BRYAN, 2008, p. 33)

É uma análise comum na historiografia o fato de que o CFESP, que atuou por dez anos, deixou seu legado para o SENAI. Um dos argumentos para essa conclusão é o fato de que a partir de 1944 Roberto Mange, primeiro diretor do Centro, foi também o diretor do departamento regional de São Paulo do SENAI (BOSCHETTI, 2006, p. 53).

Para Boschetti (2006), apesar de se manter, em grande parte, um conceito assistencialista e coercitivo sobre a formação da mão de obra trabalhadora, houve um processo de inserção do trabalhador na sociedade moderna através da ideia de formação que resultava num ensino sistemático, organizado por procedimentos metodológicos e científicos (BOSCHETTI, 2006, p. 50). A questão é se essa modernidade e cientificidade foi emancipatória ou mais adaptativa às condições vigentes. Por seu próprio princípio norteador, esse processo de formação incluiu e inseriu muitos brasileiros no mercado de trabalho a partir do modelo de desenvolvimento dominante (WEINSTEIN, 2000). 
Segundo Camoleze (2012), a educação profissional oferecida nos CFESP:

[...] estruturava uma metodologia sobre as formas de trabalho e da produção nas companhias ferroviárias, buscando uma classe homogênea de trabalhadores. Durante o período de existência dos Centros de Formações, o aspecto da educação e o trabalho traçam entre si uma interferência mútua, ambas interferindo no meio social e construindo um condicionamento à situação social vigente do indivíduo. (CAMOLEZE, 2012, p. 101)

Quando se estuda a concepção, a implantação e a extinção dos CFESP encontra-se uma série de lacunas na historiografia e mesmo na documentação. Percebe-se, como afirma Camoleze (2012), que a instituição do CFESP trouxe uma nova experiência na formação do operariado, pois era administrado e financiado por setores industriais e estatais, passando a capacitação profissional a ser não apenas de responsabilidade privada e, também, a receber apoio do poder público.

\section{AS PARCERIAS ENTRE O PÚBLICOE O PRIVADO NA FORMAC̣ÃO DO TRABALHADOR FERROVIÁRIO (1929-1948)}

A parceria entre os setores privados e públicos em torno da formação do trabalhador ferroviário é um aspecto que, nesta pesquisa, auxiliou muito na compreensão da história da educação profissional e gerou também algumas outras questões que passaremos a tratar em seguida.

Constatou-se que Roberto Mange, com a cooperação da Estrada de Ferro Sorocabana, em 1930, iniciou uma parceria com a Escola Profissional Fernando Prestes, em Sorocaba, articulada pelo diretor Basilides de Godoy, para a formação profissional de ferroviários (CARVALHO; BATISTA, 2012). Estudos no Centro de Memórias dessa escola têm permitido compreender que a Escola Coronel Fernando Prestes, cuja denominação original era Escola Profissional Mixta de Sorocaba, inaugurada em 1929, surgiu em decorrência da demanda de mão de obra para a ferrovia.

Garcia e Sandano (2013) analisando as matrículas nessa escola entre 1929 e 1942 revelam que 90\% dos alunos não concluíam os cursos. Era muito alto o índice de evasão dos cursos ferroviários, pois seus alunos rapidamente ingressavam no mercado de trabalho, deixando de frequentar a escola. Ou seja, a evasão pode ser explicada pela própria natureza da instituição escolar: formação de trabalhador qualificado, em curto espaço de tempo e com métodos eficazes de ensino e aprendizagem (GARCIA; SANDANO, 2013). 
A experiência da Escola Profissional Mixta de Sorocaba ainda é exemplar nesse sentido, paradigma para expansão do ensino ferroviário em São Paulo, no período de 1929 a 1942. Em 1929, a escola profissional atendeu menos de 2\% da população. Considerando-se o mesmo período, a população da cidade mais que dobrou (de 30.000 para 70.835), enquanto o crescimento do número de vagas oferecidas pela escola não passou dos $20 \%$ GARCIA; SANDANO, 2013). Embora fundamentais, os interesses voltados para a formação do trabalhador ferroviário mostraram-se mais úteis enquanto metodologia de ensino e aprendizagem e não propriamente quanto à estrutura administrativa ou mesmo a um plano de governo amplo e abrangente de educação profissional.

Apesar desses indicadores, que só recentemente foram revelados e analisados, as empresas férreas e o setor público consideraram a relevância dos cursos profissionalizantes para a formação do trabalhador ferroviário com currículos específicos, aplicações de testes vocacionais e estágios nos locais de aprendizagem. Educadores, engenheiros e participantes do Instituto e Organização Racional do Trabalho (IDORT) passaram nos anos de 1930 a elaborar um plano para viabilizar a sua expansão.

Esse plano de expansão foi avaliado por Horácio Augusto da Silveira, diretor do Instituto Profissional Feminino, em São Paulo, na capital. Foram realizadas inúmeras reuniões na Secretaria de Viação e Obras Públicas com diretores de estradas de ferro, um secretário de Viação e Obras Públicas, com diretores de estradas de ferro, um representante da Secretaria da Educação e sempre com a participação do engenheiro Roberto Mange (CARVALHO; BATISTA, 2012).

Desse estudo surgiu o Decreto Estadual n. 6.537, de 04 de julho de 1934, que criou cursos de ferroviários e determinou outras medidas, como contribuição do estado ao CFESP, organizando sob os auspícios do governo do estado os cursos nas escolas profissionais de São Paulo, Campinas e Rio Claro e criando os Núcleos de Ensino Profissional em Jundiaí, Araraquara, Bauru e no bairro da Lapa, na capital, com abertura possível de outras instituições conforme a necessidade local e a solicitação do CFESP.

Esse decreto anunciou as novas medidas considerando, nos seus termos, o seguinte contexto:

[...] a formação e a seleção profissional do pessoal de transportes públicos como funções da mais alta responsabilidade e de grande interesse coletivo. [...] a grande vantagem econômica e social de um sistema de cooperação entre todos os elementos interessados: Estradas de Ferro, o Governo, as municipalidades e as empresas industriais. (SÃO PAULO, 1934) 
Com base nesse decreto, Horácio Augusto da Silveira, interino, e posteriormente primeiro Superintendente do Ensino Profissional e Doméstico no estado de São Paulo, propõe uma organização funcional para administrar o ensino profissional, que inclui o CFESP (CARVALHO; BATISTA, 2012). Essa instituição, segundo dados da historiografia, teria sido extinta pelo Decreto n. 18.087, de 20 de abril de 1948 (SÃO PAULO, 1948). Essa extinção seria explicada pela criação do SENAI em 1942.

O caso de Sorocaba e a posterior implantação do CFESP são exemplares para se analisar a aproximação entre o poder público e as companhias férreas no sentido de formar o trabalhador ferroviário. Mas, nem sempre essa aproximação foi percebida com clareza ou vivenciada de forma a integrar a escola pública com os interesses locais e das companhias férreas (CARVALHO; BATISTA, 2012; KAMAZAWA, 2013).

Como algo que teve sua expansão legitimada em 1934 seria substituído em 1942 por outra instituição não governamental e, finalmente, extinto em 1948?

Para Bryan (1983), a criação do SENAI constituiu-se como uma extensão a todo o setor industrial da experiência do ensino ferroviário. Essa extensão foi tornada compulsória pelas ações estatais, tendo como principal objetivo assegurar ao capital o controle da formação técnica e ideológica da força de trabalho por meio da conciliação das propostas da burocracia governamental e dos representantes do capital industrial.

Nesse sentido, o SENAI aparece como um momento de síntese, sem contradições. Uma espécie de continuidade do ensino ferroviário do ponto de vista metodológico, mas agora de responsabilidade dos industriais que então, frente à obrigatoriedade legal, assumiram as diretrizes da educação profissional.

Para a historiografia sobre educação profissional no estado de São Paulo, os cursos de ferroviários da Estrada de Ferro Sorocabana teriam sido um grande laboratório e uma demonstração prática dos projetos essenciais de Roberto Mange, seja para a criação do CFESP, em 1934, seja para a criação do SENAI, em 1942. Mas, se há afinidades históricas e ideológicas, é importante destacar que a implantação do SENAI não é simples continuidade das experiências paulistas em termos de educação profissional, nem houve total rompimento do poder público com a formação do trabalhador ferroviário a partir da criação dessa instituição.

Em termos gerais, problematizando o que Bryan (1983) pôde constatar, o que se observa nesse processo é um conflito entre os industriais paulistas, o Ministério da Educação e o Ministério do Trabalho. Schwartzman, Bomeny e Costa (2000), analisando o 
processo pelo qual foi implantado o SENAI e a Lei Orgânica da Educação Nacional de 1942, afirmam a complexidade desse momento das políticas públicas voltadas para a educação profissional:

Havia três grandes ambições. A maior era a criação de um amplo sistema de educação
profissional, que não se diferenciasse das outras formas de educação secundária
a não ser pelas diferentes "vocações" dos estudantes, a serem descobertas pelos
sistemas de seleção e orientação profissional. Este sistema deveria ser coroado
pela regulamentação dos direitos e deveres de cada uma das profissões, dando
à sociedade uma estrutura corporativa perfeitamente ajustada e coordenada.
Na prática, a educação profissional continuou sendo uma educação para as classes
baixas, e a regulamentação das profissões técnicas não foi conseguida. A segunda
ambição era colocar todo o sistema sob a tutela do Ministério da Educação e
Saúde. Aqui, o Ministério do Trabalho e a Federação das Indústrias se mostraram
mais fortes e conseguiram criar seu sistema de educação profissional como
achavam mais conveniente: de forma mais pragmática, mais ajustada a seus
interesses imediatos e livres da tutela ministerial. A terceira, finalmente, era a da
escola-modelo para a definição de padrões de excelência, que fosse para o ensino
industrial o que o Colégio Pedro II fora para o secundário, e o que a Universidade
do Brasil deveria ser para o superior. Aqui, a ausência de uma tradição de ensino
profissional anterior, a não consideração dos processos reais de aprendizagem e a
crença ingênua nos efeitos dos grandes projetos são os responsáveis pelo fracasso.
(SCHWARTZMAN; BOMENY; COSTA, 2000, p. 234)

Os conflitos explicitados por esses autores, além de problematizarem a relação de continuidade entre o ensino ferroviário e o SENAI, ressaltam que considerar a educação profissional como uma educação para as classes baixas não deve ser confundida e alinhada com o ensino aos humildes, pobres e desvalidos. Não se pode considerar a elitização e o dualismo da educação profissional tal e qual era antes no Brasil Colonial e Imperial. Se os anos de 1930 tiveram como marco para o ensino profissional a experiência considerada bem-sucedida do trabalhador ferroviário em parceria com os setores públicos e privados, nos anos de 1940, para a educação, o chamado tempo de Capanema, buscou-se solucionar conflitos delimitando mais claramente o que era dever do Estado e dever das empresas. Esse processo de uma melhor delimitação não é simples de compreender e lança questões importantes.

Se entre 1942, com a criação do SENAI, e 1948, com o Decreto n. 18.087, de 20 de fevereiro de 1948, de extinção do CFESP, começa o processo de transição, transferindo-se a responsabilidade de orientação técnica dos cursos de ferroviários das escolas profissionais da Superintendência do Ensino Profissional para o SENAI, por que isso não teria ocorrido quanto aos cursos oferecidos em Sorocaba? Qual é a efetiva relação entre os cursos ferroviários 
oferecidos pela Estrada de Ferro Sorocabana, o CFESP e o SENAI? Se a experiência de formação do trabalhador ferroviário em Sorocaba foi paradigmática para o CFESP e para o SENAI, por que a primeira unidade do SENAI só surgirá na cidade em 1962? Essas questões não são apenas problemas de pesquisa, mas verdadeiras lacunas da historiografia sobre educação profissional em São Paulo.

Para compreender esse processo através de outras fontes foi realizada uma entrevista com o diretor Mario Ianeta da Escola Técnica Getúlio Vargas, em 19 de janeiro de 2012. Ele foi aluno da primeira turma do curso Técnico de Eletrotécnica, nessa escola, entre 1941 e 1943. Seu depoimento permite confirmar que o Serviço de Psicotécnica já existia na Superintendência do Ensino Profissional, nessa época. Mas, conforme seu relato os cursos especificamente voltados para a formação do trabalhador ferroviário não eram vistos como integrados ao cotidiano dessa escola.

Num contexto de mais oportunidades de formação e de formação para o trabalho, Mário Ianeta relativiza a importância dos cursos ferroviários. Porém, a extinção oficial do CFESP atribuída ao Decreto n. 18.087, de 20 de abril de 1948, não significou um total descompromisso do Estado com a formação do trabalhador ferroviário. Estudos sobre o ensino ferroviário em Pindamonhangaba realizados por Ribeiro, Teixeira e Magalhães (2013) revelam que houve apenas uma alteração na administração escolar, sendo a escola ferroviária, a partir de 1948, gerida unicamente com os recursos da Estrada de Ferro Campos do Jordão, propriedade do Estado.

Segundo as pesquisadoras, a extinção do Núcleo Ferroviário de Pindamonhangaba só ocorreria no fim dos anos de 1960. No início dos anos de 1950, conforme documentado no jornal local Tribuna do Norte, a resistência era muito significativa no sentido de se manter o Núcleo Ferroviário. O jornal documenta em 18 de dezembro de 1951 a reivindicação da Secretaria da Viação e Obras públicas do município, na pessoa de seu secretário Nilo Andrade Amaral. O seu ofício se apresenta nos seguintes termos:

\footnotetext{
Não convém a extinção do Núcleo de Ensino Ferroviário mantido pela Estrada, visto destinar-se ele à fundação de artífices especializados nos serviços ferroviários, funcionando o Curso Prático de Aprendizagem em suas próprias oficinas. O referido Núcleo que vem sendo dirigido sob a orientação da Comissão Orientadora dos Serviços de Ensino e Seleção Profissional das Estradas de Ferro Estaduais... tem ministrado eficiente ensino profissional e uma boa plêiade de artífices que nele se diplomara e já se acham integrados nos quadros da referida ferrovia. (AMARAL, 1951, citado por RIBEIRO; TEIXEIRA; MAGALHÃES; 2013, p. 212)
} 
Essa situação se explica se tivermos como horizonte o contexto histórico e normativo do Decreto n ${ }^{\circ} 17.698$, de 26 de novembro de 1947, que, em seus Artigos n. 878 a n. 899 trata dos cursos de ferroviários e dos núcleos de ensino profissional no estado de São Paulo (SÃO PAULO, 1947).

Segundo esse decreto, para a formação do pessoal de oficinas ferroviárias, o Estado deveria manter cursos de ferroviários, anexos às escolas industriais em Ribeirão Preto, Sorocaba, e na Escola Técnica Getúlio Vargas, da capital; núcleos de ensino profissional, nas cidades de Araraquara, Bauru, Bebedouro, Cruzeiro e Pindamonhangaba.

A dúvida que fica na leitura desses decretos é sobre a extinção ou não do CFESP. O que se percebe, no período entre o decreto de 1934 e o decreto de 1948, é que o CFESP foi muito mais um modelo político pedagógico de educação profissional em parte incorporado pelas escolas públicas e base para a reorganização futura, seja do SENAI, seja da continuidade dos projetos das escolas profissionais. O CFESP teria representado a unificação/uniformização/padronização dos métodos de ensino e aprendizagem sob o controle/orientação das estradas de ferro paulistas. Para outros estados (do Ceará ao Rio Grande do Sul) o CFESP ofereceu às ferrovias assistência técnica, por meio de publicações especiais, ações padronizadas, desenhos das séries metódicas de aprendizagem ou diretamente dos seus técnicos (BATISTA, 2009).

O Decreto n. 18.087 de 1948 documenta o fim da parceria pública com o setor privado quanto ao ensino profissional ferroviário, algo que já ficara estabelecido no Decreto n. 14.550, de 21 de fevereiro de 1945 , em seus Artigos $1^{\circ}$ e $4^{\circ}$, a saber:

Artigo $1^{\circ}$ - Fica criado, em cada uma das estradas de ferro de propriedade e administração do Estado Estrada de Ferro Sorocabana, Estrada de Ferro Araraquara, Entrada de Ferro Campos do Jordão e Estrada de Ferro São Paulo e Minas - de acordo com o decreto-lei federal n. 4.984, de 21 de novembro de 1942, um Serviço de Ensino e Seleção Profissional, ao qual competirá a formação profissional de seus aprendizes e o ensino de continuação e de aperfeiçoamento e especialização de seu pessoal.

Parágrafo único - Esses serviços de Ensino e Seleção Profissional ficam subordinados as respectivas estradas de ferro, que os manterão por conta de seus orçamentos.

Artigo $2^{\mathbf{o}}$ - No que diz respeito à organização e diretrizes pedagógicas dos cursos ferroviários a serem mantidos pelos Serviço de Ensino e Seleção Profissional, serão observadas as disposições básicas da Lei Orgânica do Ensino Industrial e dos decretos-leis federais querem a aprendizagem industrial.

Parágrafo único - Esses Serviços de Ensino e Seleção Profissional serão regulamentados pela forma estabelecida no mencionado decreto-lei federal n. 4.984. 
Artigo $3^{0}$ - Os Serviços de Ensino e Seleção Profissional referidos no art. $1^{\circ}$, articular-se-ão, para fins de unificação da orientação técnica e pedagógica, com o Serviço de Ensino e Seleção Profissional, da Estrada de Ferro Sorocabana.

Artigo $4^{\mathbf{0}}$ - As diretrizes gerais dos Serviços de Ensino e Seleção Profissional, nessas estradas de ferro, serão lixadas, e fiscalizada sua execução, por uma Comissão Orientadora. (SÃO PAULO, 1945)

É importante que se entenda, portanto, que o Decreto n. 18.087, de abril de 1948, não encerra a experiência do CFESP, mas extingue os cursos ferroviários e os núcleos de ensino profissional, anteriormente orientados e desde 1947 regulamentados pelo Decreto n. 17.698, com o detalhamento do funcionamento do Serviço de Ensino e Seleção Profissional nas estradas de ferro estatais.

Segundo o parágrafo único do Artigo $2^{\circ}$ do Decreto n. 14.550, de 21 de fevereiro de 1945, e como mencionado já no artigo $1^{\circ}$, esses Serviços de Ensino e Seleção Profissional deveriam seguir a regulamentação do Decreto-lei federal n. 4984. Esse decreto em seu Artigo $1^{\circ}$. Determina que

\footnotetext{
Cada estabelecimento industrial da União, dos Estados, do Distrito Federal e dos Municípios, que disponha de organização permanente, com mais de cem empregados, deverá, a partir de 1943, manter, por conta de seu próprio orçamento, uma escala ou um sistema de escolas de aprendizagem, destinada à formação profissional de seus aprendizes e ao ensino de continuação e de aperfeiçoamento e especialização de seus demais trabalhadores. (BRASIL, 1945)
}

Assim, ele indica que estabelecimentos industriais públicos com mais de cem empregados e organização permanente desenvolvam ações para formação profissional, aperfeiçoamento e especialização, conforme aprovação presidencial e do Ministério da Educação. Quanto ao SENAI, será permitido e não obrigatório "que os estabelecimentos industriais oficiais, para efeito da administração de seu ensino, se articulem com o sistema das escolas de aprendizagem incluídas no Serviço Nacional de Aprendizagem Industrial.” (BRASIL, 1945).

Isso explica o porquê da entrada tardia do SENAI em Sorocaba, nos anos de 1960, a permanência do Núcleo Ferroviário em Pindamonhangaba até final dos anos de 1970 e a incorporação em Jundiaí da escola ferroviária ao SENAI já nos anos de 1940. Sendo uma companhia particular até sua anexação à FEPASA em 1971, a Companhia Paulista não fazia parte dos programas viabilizados nas estradas de ferro do governo paulista, ao contrário da Estrada de Ferro Sorocabana, que, entre idas e vindas do setor privado ao setor público, teve o governo de São Paulo assumindo novamente seu controle no dia 9 de setembro de 1919. 
ESTUDO SOBRE A FORMAC̣ÃO DO TRABALHADOR FERROVIÁRIO NAS ESTRADAS DE FERRO PÚBLICAS A PARTIR DA EXTINCূÃO DO CFESP: CONTRIBUIC̣ÃO DAS REVISTAS FERROVIÁRIAS PARA A COMPREENSÃO DOS ANOS DE 1940 A 1960

O esforço até o momento deste estudo foi compreender em que contexto institucional e normativo ocorreu a continuidade desses cursos que nos anos de 1940 a 1960, em Sorocaba, não estavam subordinados ao SENAI. Demonstra-se que a partir dos artigos publicados nesse período na Revista Nossa Estrada e na Revista Ferroviária acerca da formação profissional do trabalhador ferroviário é possível lançar luzes para algumas respostas e novos estudos. ${ }^{2}$

As revistas ferroviárias são importantes documentos históricos relativos à trajetória das companhias férreas brasileiras. Havia a preocupação por parte dessas companhias em registrar e divulgar seus avanços tecnológicos e, em termos de expansão geográfica, seus investimentos financeiros e notícias relativas aos empregados. Na biblioteca do Museu da Companhia Paulista em Jundiaí - SP há um acervo importante dessas revistas, destacando-se as boas condições arquivísticas da Revista Ferroviária e da Revista Nossa Estrada (MUSEU DA COMPANHIA PAULISTA, 2015).

A pesquisa documental foi realizada com as edições de 1940, 1942 e 1943 da Revista Ferroviária e com as edições de 1944 e 1965 da Revista Nossa Estrada. Os indicadores do acervo dessas revistas no Museu da Companhia Paulista em Jundiaí podem ser acessados pela base de dados do Projeto Memória Ferroviária (Figura 1):

FIGURA 1

Base de dados do Projeto Memória Ferroviária

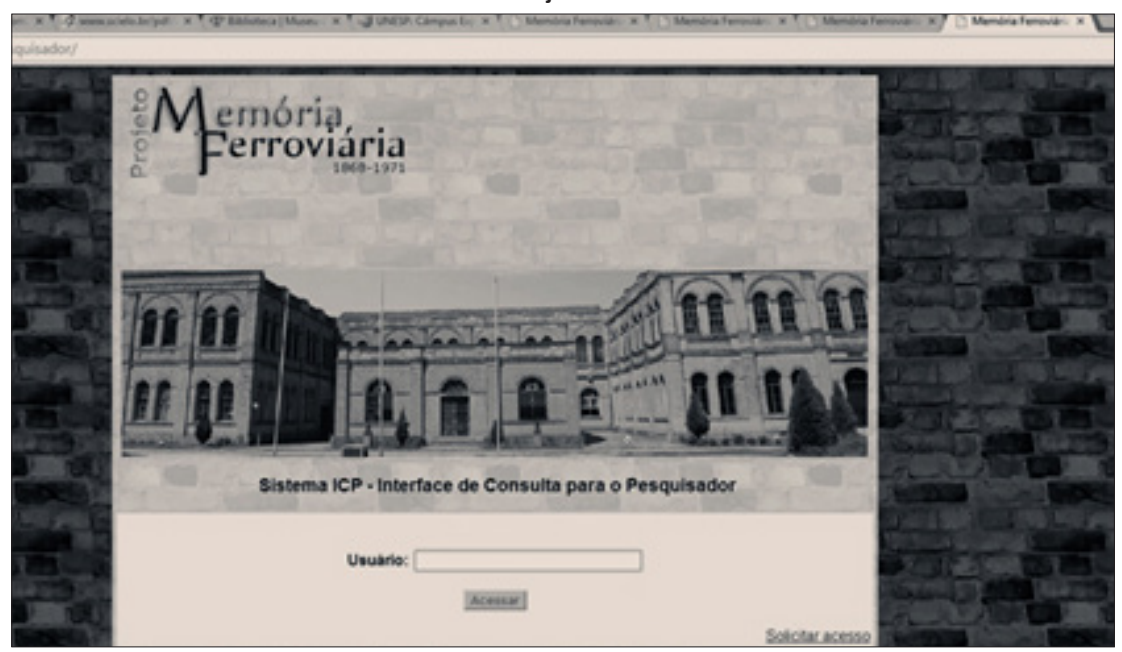

Fonte: Museu da Companhia Paulista, 2015. 
Os periódicos consultados foram produzidos pelas Companhias Férreas e/ou associações a elas ligadas, que tratam dos mais diversificados assuntos de interesse administrativo, tecnológico e educacional. Destacam-se as matérias sobre o histórico e os resultados das escolas e dos cursos ferroviários. Aliado ao estudo da historiografia ainda escassa sobre o tema, a leitura e análise dos artigos publicados nessas revistas podem elucidar questões importantes quanto ao ensino profissional público e privado voltado para as necessidades de mão de obra das empresas férreas.

A Revista Nossa Estrada foi uma publicação oficial da Estrada de Ferro Sorocabana até 1972. A partir desse ano, passou a publicar notícias de todo o complexo ferroviário paulista anexado à empresa Ferrovias Paulistas S/A (FEPASA). No acervo da biblioteca do Museu da Companhia Paulista em Jundiaí há um corpus documental dessa revista que abrange o período de 1933 a 1981.

A Revista Ferroviária foi lançada em janeiro de 1940 no Rio de Janeiro, pelo engenheiro Ruben Vaz Toller, da Estrada de Ferro Central do Brasil, filho de Jacinto Toller, proprietário da gráfica Pimenta de Melo, que entre outras publicações rodava a revista política $O$ Malho. A Revista Ferroviária surgiu como órgão da Associação de Engenheiros da Estrada de Ferro Central do Brasil, que na época concluíra a eletrificação do subúrbio do Rio de Janeiro. Pouco tempo depois, Jorge de Moraes Gomes assume a revista, cria uma empresa editora - Empresa Jornalística dos Transportes Ltda. - e a dirige até 1984. Nessa data, assume a editora o jornalista Gerson Toller, que a dirige até os dias atuais (REVISTA FERROVIÁRIA, 2013). Ela é tida como a revista mais antiga do Brasil publicada por uma editora privada com circulação regular (bimestral). A Revista Ferroviária cobre a atualidade dos transportes ferroviário, metroviário e metropolitano no Brasil e se interessa pela preservação do material ferroviário de interesse histórico. No acervo da biblioteca do Museu da Companhia Paulista em Jundiaí há um corpus documental dessa revista que abrange o período de 1940 a 1994.

A Revista Ferroviária publicada em julho de 1940 traz informações importantes sobre os cursos ferroviários superiores, quase não mencionados pela historiografia. Segundo dados publicados nessa edição, já eram tradicionais em 1940 os cursos superiores de aperfeiçoamento técnico para engenheiros das companhias férreas. Os objetivos desses cursos promovidos pelo CFESP eram tornar conhecidos os estudos e as experiências, divulgar os resultados obtidos a partir desses conhecimentos em cada ramo da engenharia ferroviária, estudar as normas administrativas adequadas a cada setor 
de sua atividade e proporcionar o conhecimento in loco da organização dos processos de trabalho. Esses cursos tinham periodicidade anual, ocorriam nas dependências da Estrada de Ferro Sorocabana e aconteciam num intervalo de 20 a 25 dias.

A Revista Ferroviária de janeiro de 1942 documenta que foi criada em 22 de setembro de 1941 a Divisão de Ensino e Seleção Profissional para a Estrada de Ferro Central do Brasil, assim como ocorreria mais tarde em São Paulo. Também menciona os cursos superiores de aperfeiçoamento técnico na Estrada de Ferro Sorocabana, entre 02 e 25 de outubro de 1942. Os cursos teriam sido frequentados por engenheiros e técnicos de várias estradas. Os palestrantes eram engenheiros da Companhia Paulista, da Central do Brasil, da Mogiana e da Sorocabana. Percebe-se que, seguindo a legislação, a despeito das iniciativas do SENAI, as companhias férreas estatais continuaram a desenvolver ações conjuntas de formação e aperfeiçoamento de pessoal.

$\mathrm{Na}$ Revista Ferroviária de janeiro de 1943, ainda se menciona a importância do CFESP, que, por iniciativa do IDORT e da colaboração entre diversas ferrovias, teria as seguintes atribuições:

[...] proporcionar às estradas nacionais o conhecimento dos meios de ampliar as condições de segurança do tráfego sobre trilhos através da formação racional de seu pessoal; [...] organizar sistematicamente o ensino ferroviário quer em cursos especializados sobre cada atividade, ou através de intercâmbio entre o pessoal; [...] coordenar as ações que já existiam neste sentido na Paulista, na Sorocabana, na EFCB, na Rede Paraná Santa Catarina, passando a obedecer normas modernas. (REVISTA FERROVIÁRIA, 2013)

Essa edição procura justificar a criação do CFESP devido ao tamanho da malha ferroviária e ao número de empregados, dos quais quase metade estava atuando em serviços de importância vital (reparação do material rodante, controle de circulação, condução das locomotivas e trens). O CFESP, mesmo em 1943, segundo artigo da Revista Ferroviária, ainda podia ser um exemplo do que ocorria em outros países perante a necessidade de criar órgãos com a finalidade de colocar cada trabalhador em seu lugar, segundo as aptidões físicas e mentais e os índices de caráter e preferência.

Essa edição ainda documenta que em 1943 eram filiadas ao centro todas as estradas férreas de São Paulo, a Central do Brasil, a Rede Paraná-Santa Catarina, a Rede Mineira de Viação, a Great Western, a Viação Cearense, a Estrada de Ferro Goiás, a Leste Brasileiro Nazaret e a Viação Férrea Rio Grande do Sul, articulando 73\% do tráfego das empresas e $83 \%$ da população ferroviária. Suas ações até aquela data foram: formação de artífices; seleção dos alunos por meio de exame 
médico; exame de provas de aptidão e de conhecimento; formação de grupos especializados nos diferentes ofícios (ajustadores, ferreiros, carpinteiros, operadores mecânicos); oferecimento de cursos de aperfeiçoamento aos mestres de oficina; para chefes de escritório; de via permanente e de tráfego, do preparo dos operários, técnicos e engenheiros através do Curso Superior de Locomoção, subsídio para elaboração de fichas e avaliações que viabilizavam: promoções, acesso aos cargos, indicação dos mais aptos.

É interessante observar que essas revistas não falam de propriamente da extinção do CFESP, mas de uma continuidade dele a partir do Serviço de Ensino e Seleção Profissional. Assim o é que, na Revista Nossa Estrada, Ano XVI, números 77 e 78, publicados no ano de 1944, há um texto do engenheiro Ruy Costa Rodrigues sobre as leis do ensino profissional. Nesse texto, o engenheiro ressalta que:

Vem se desenvolvendo a legislação do ensino profissional no nosso País, desde a criação, melhoramento e sistematização das Escolas Profissionais - até a criação do 'Senai' e a obrigatoriedade pelas estradas de ferro do Estado, da criação e manutenção do Serviço de Ensino e Seleção Profissional e, agora, na estrutura do sistema Federal de Ensino, a 'Escola Técnica Nacional' vem preencher, dentro do ensino profissional, uma grande lacuna - a da formação dos Condutores Técnicos, que constituem o intermediário entre o engenheiro e o operário. (RODRIGUES, 1944, p. 25)

Nesse trecho em particular, e de forma geral na abordagem dessas revistas, há mais ênfase no aperfeiçoamento técnico dos operários, em sua especialização e formação contínua oferecida por iniciativa do CFESP, do que na formação dos operários das oficinas. O que Ruy Costa Rodrigues ressalta como formação dos condutores técnicos é ratificado pelas pesquisas de Tenca (2006):

Reforçava-se, assim, nos cursos de curta duração, aquilo que acabou se confirmando como um dos principais objetivos do Curso de Ferroviários: a formação 'técnico-científica dos chefes'. [...] Treinados e cobrados, no lugar da aprendizagem, para produzir as peças buscando otimizar o fazer quanto ao tempo, precisão nas medidas e acabamento, muitos desses aprendizes de ferroviários acabaram por desenvolver, no lugar do fazer, uma habilidade no olhar para identificar problemas na rotina do trabalho e solucioná-los de acordo com as máximas orientadoras do curso. (TENCA, 2006, p. 301)

O CFESP foi responsável em grande medida pela formação dos gestores dirigentes nas companhias férreas. Esse dado é possível de ser levantado e analisado a partir de relatos orais de ex-ferroviários que trabalharam em vias permanentes e oficinas e que não tiveram formação técnica alguma ${ }^{3}$. 
A revista Nossa Estrada em edição de 1965, fazendo um resgate dessa história, afirma que o CFESP surgiu de um plano de cooperação entre o governo do estado e as estradas férreas de São Paulo em 1934, sendo mantido por uma contribuição proporcional ao número de empregados de cada companhia férrea associada. Tinha como função racionalizar o ensino e a seleção profissional. Com o surgimento do SENAI, que assumiu essa responsabilidade perante as ferrovias federais, coube ao estado de São Paulo criar o seu próprio sistema.

Segundo essa edição da revista, coube à Divisão de Ensino Profissional da Estrada de Ferro Sorocabana a tarefa de dirigir e orientar o trabalho relativo ao ensino ferroviário nas estradas de ferro de propriedade do Estado. Dessa forma, essa divisão passou a oferecer cursos para ferroviários em Assis, Botucatu, Itaici, Sorocaba, Itapetininga, Presidente Prudente, Santos e Barra Funda, também orientando os cursos de Campos do Jordão, Araraquara e de cidades atravessadas pela Estrada de Ferro São Paulo-Minas.

A divisão de Ensino e Seleção Profissional tem sua abrangência geográfica e atribuições específicas demonstradas na Figura 2, abaixo:

\section{FIGURA 2}

Cursos ferroviários vinculados à Divisão de Ensino Profissional da E.F. Sorocabana (Revista Nossa Estrada, 1965)

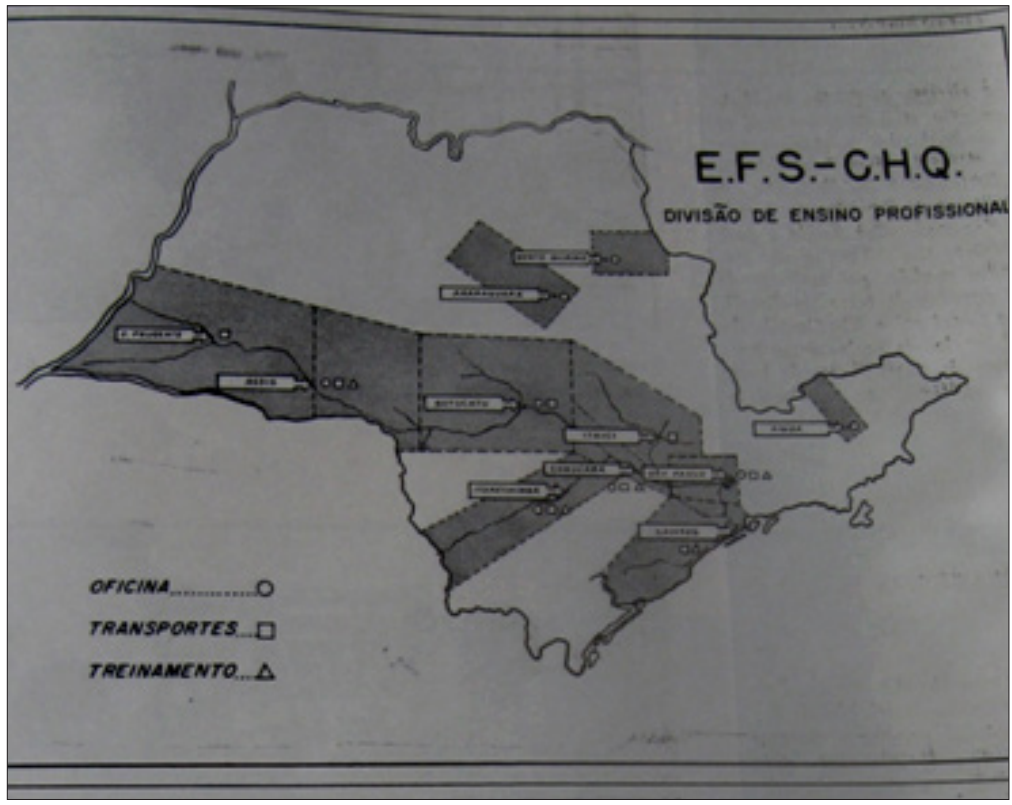

Fonte: Museu da Companhia Paulista, 2015. 
Os objetivos dessa divisão são apresentados como os de formar pessoal especializado para o serviço de transportes e oficina e aperfeiçoar o pessoal técnico por meios de cursos de treinamento e aperfeiçoamento.

\section{CONSIDERACְÕES FINAIS}

Dos primeiros estudos sobre a formação do trabalhador ferroviário procurou-se avançar quanto às rígidas delimitações como as que identificam, de um lado, o patrimônio industrial ferroviário e, do outro lado, o patrimônio educativo. Também apontamos para o fato que a formação do trabalhador ferroviário foi uma importante experiência para estudar os limites e as possibilidades das relações entre o mundo do trabalho e o da escola. Em alguns momentos, nesse processo de formação, o mundo do trabalho e o mundo da escola parecem indistintos. Encontram-se espaços comuns ou intercambiados, distanciamentos e aproximações entre o público e o privado do ponto de vista da legislação e de experiências locais, lideranças políticas e empresariais, que aparecem na historiografia mais do que os educadores e teóricos da educação.

A trajetória de pesquisa e os resultados alcançados aqui registrados não seriam possíveis não fossem as parcerias entre grupos e projetos de pesquisa, tais como o envolvimento dos docentes do GEPEMEP e sua aproximação com o Núcleo de Estudos de Tecnologia e Sociedade (NETS), além da inserção no Projeto Memória Ferroviária da temática tecnologia e cultura, na qual somos responsáveis pelos estudos relativos à educação profissional enquanto memória da formação e da cultura do trabalho.

Algumas questões permanecem em aberto aguardando novos estudos. Outras questões surgem a partir do amadurecimento da pesquisa. O material didático oferecido pelo CFESP merece estudos mais específicos, bem como a legislação específica cujas lacunas ainda não podemos compreender totalmente.

As revistas ferroviárias ao longo dos anos, talvez devido ao processo de decadência do modal ferroviário, vão deixando de tratar especificamente das questões técnicas e administrativas das ferrovias, para inserir contos, propagandas, curiosidades e demais assuntos de interesse geral, sem deixar de manifestar que tipo de trabalhador e de processo de produção se pretende valorizar e difundir.

Os relatos orais acerca da formação do trabalhador ferroviário têm apontado para os limites dessa formação do ponto de vista de um 
efetivo acesso dos jovens aos cursos. Os estudos já iniciados sobre a evasão nesses cursos, sobre as disciplinas e a divisão social do trabalho presente nas grades curriculares também são temas a serem aprofundados.

Os estudos aqui apresentados revelam o grande interesse das companhias férreas em formar trabalhadores qualificados, condutores técnicos, a partir de cursos de aperfeiçoamento. Isso revela que a formação do trabalhador ferroviário foi pautada não necessariamente por um programa de emancipação e promoção do trabalhador como um todo, mas num processo de seleção dos que, de alguma forma, tinham condições de caminhar juntamente com o progresso da engenharia ferroviária.

\section{REFERÊNCIAS}

BATISTA, Maristela Iurk. O Estado Novo e as novas perspectivas no processo educacional brasileiro: os reflexos na expansão do ensino ferroviário (1937-1945), 2009. Disponível em: <http:/ /www. histedbr.fae.unicamp.br/acer_histedbr/seminario/seminario6/Escolas, $\% 20$ Cursos $\% 20$ e\%20Programas \%20\%20Especiais/Estado\%20Novo....doc>. Acesso em: 30 abr. 2012.

BATISTA, Sueli S. S. Estudo sobre a escola de aprendizes ferroviários da companhia paulista em Jundiaí nos primeiros anos da República. In: CONGRESSO BRASILEIRO DE HISTÓRIA DA EDUCAÇÃO, 7., 2011, São Luís. Anais... São Luís: UFMA.Disponível em: <http://www.sbhe.org.br/novo/congressos/cbhe6/anais_vi_cbhe/conteudo/res/ trab_408.htm>. Acesso em: 17 ago. 2014.

BOSCHETTI, Vânia Regina. O curso ferroviário da Estrada de Ferro Sorocabana. Revista Histedbr. Campinas, n. 23, p. 46-58, set. 2006.

BOSCHETTI, Vânia Regina; MACEDO, Samara Eliza; AMARO, Vanelli Pires. Fundindo, tecendo, trilhando...: aspectos da educação profissional em Sorocaba, 2006. Revista Histedbr. Campinas, n. 21, p. 131-140, mar. 2006. Disponível em: <http://www.histedbr.fe.unicamp. br/revista/edicoes/21/art12_21.pdf>. Acesso em: 20 mar. 2013.

BRASIL. Decreto-Lei $n^{\circ} 4.984$, de 21 de novembro de 1942. Dispõe sobre a aprendizagem nos estabelecimentos industriais da União, dos Estados, do Distrito Federal e dos Municípios. Disponível em: <http://www2.camara.leg.br/legin/fed/declei/1940-1949/decreto-lei4984-21-novembro-1942-415010-publicacaooriginal-1-pe.html>. Acesso em: 20 abr. 2013.

BRYAN, Newton Antonio Paciulli. Educação e processo de trabalbo: contribuição ao estudo da formação da força de trabalho no Brasil. 1983. 232 f. Dissertação (Mestrado em Educação), UNICAMP, Campinas, 1983.

. O ensino ferroviário. In: . Educação, processo de trabalho e desenvolvimento econômico. Campinas: Alínea Editora, 2008.

CAMOLEZE, Jean Marcel. Andando nos trilhos: formação educacional e resistência dos trabalhadores na Companhia Paulista de Trens de Jundiaí, 1931-1942. In: SIMPÓSIO INTERNACIONAL DE HISTÓRIA PÚBLICA: A HISTÓRIA E SEUS PÚBLICOS, 1. 2012, São Paulo. Anais... São Paulo: Universidade de São Paulo. Disponível em: <https:// redebrasileiradehistoriapublica.files.wordpress.com/2013/01/a-histc3b3ria-e-seuspc3bablicos-_-anais.pdf>. Acesso em: 10 jul. 2015. ISBN 978-85-62959-25-7. 
CAMPOS, Cristina. Escolas profissionais e oficinas ferroviárias: uma história social da transferência da tecnologia ferroviária em São Paulo, 2013. Disponível em: <www.sbhc.org. br/.../1345078859_ARQUIVO_Artigo_Cristina_SBHC_2>. Acesso em: jan. 2013.

CARVAlHO, Maria Lúcia Mendes de; BATISTA, Sueli Soares dos Santos Batista. Patrimônio, trabalho e educação: o Centro Ferroviário de Ensino e Seleção Profissional (1934 a 1948). In: COLÓQUIO LATINO AMERICANO SOBRE RECUPERAÇÃO E PRESERVAÇÃO DO PATRIMÔNIO INDUSTRIAL, 6., 2012, São Paulo. Anais... São Paulo: Centro Universitário Belas Artes de São Paulo, 2012, p. 27-30.

CIAVAT'TA, Maria. Mediações históricas de trabalho e educação: gênese e disputas na formação dos trabalhadores (Rio de Janeiro, 1930-1960). Rio de Janeiro: Lamparina, 2009.

CUNHA, Luiz Antônio. O ensino de oficios nos primórdios da industrialização. São Paulo: Ed. UNESP, 2005.

FONSECA, Celso Suckow da. História do Ensino Industrial no Brasil. Rio de Janeiro: SENAI/ DN/DPEA, 1986.

FRIGOTTO, Gaudência; CIAVATTA, Maria; RAMOS, Marise. A política de educação profissional no Governo Lula: um percurso histórico controvertido. Revista Educação e Sociedade. Campinas, v. 26, n. 92, p. 1.087-1.113, Especial - out. 2005.

GARCIA, J. R.; SANDANO, W. A Escola Profissional Mixta de Sorocaba: aspectos sobre o processo ensino-aprendizagem (1929-1942). In: CARVALHO, M. L. M. de (Org.). Patrimônios, currículos e processos formativos. São Paulo: Centro Paula Souza, Imprensa Oficial, 2013.

GEPEMHEP. Percurso histórico, 2015. Disponível em: <http://www.cpscetec.com.br/ memorias/arquivos/gepemhep.pdf>. Acesso em: 20 abr. 2015.

KAMAZAWA, Julia N. A criação da Escola Profissional Agrícola-Industrial Mista de Jacarehy e a Estrada de Ferro Central do Brasil. In: CARVALHO, Maria Lúcia Mendes de (Org.). Patrimônios, currículos e processos formativos. São Paulo: Centro Paula Souza, Imprensa Oficial, 2013. MEDEIROS, M. M. Expansão capitalista e ensino profissional. Rio de Janeiro: SENAI/DN/DPEA, 1987. MUSEU DA COMPANHIA PAULISTA. Projeto Memória Ferroviária - Base de Dados, 2012. Disponível em: <http://www.rosana.unesp.br/\#!/pesquisa/laboratorio-de-patrimoniocultural/projetos/projeto-memoria-ferroviaria-pmf/base-de-dados-de-documentacao/ $>$. Acesso em: 20 mar. 2015.

RANGEL, Carlos Roberto da Rosa. Estudo comparativo da educação profissionalizante entre os ferroviários gaúchos e paulistas. Revista de História Comparada. Rio de Janeiro, v. 3, n. 1, p. 1-21, 2009. Disponível em: < http://www.hcomparada.historia.ufrj.br/revistahc/ artigos/volume003_Num001_artigo007.pdf>. Acesso em: 20 abr. 2015.

REVISTA FERROVIÁRIA. Histórico. Disponível em: <www.revistaferroviaria.com.br>. Acesso em: 10 maio 2013.

RIBEIRO, C. A.; TEIXEIRA, L. S.; MAGALHÃES, P. C. Do ensino ferroviário ao ensino industrial: transformações ocorridas entre 1948 e 1974. In: CARVALHO, M. L. M. de (Org.). Patrimônios, currículos eprocessos formativos. São Paulo: Centro Paula Souza, Imprensa Oficial, 2013. SALVADORI, Maria Ângela Borges. Educação, trabalho e juventude: os Centros Ferroviários de Ensino e Seleção Profissional e o perfil do jovem ferroviário. Revista Histórica. São Paulo: ano 2, n. 11, p. 9-19, jun. 2006. Disponível em: <http://www.historica.arquivodoestado. sp.gov>. Acesso em: mar. 2013.

SÃO PAULO. ASSEMBLEIA LEGISLATIVA DO ESTADO DE SÃO PAULO. SECRETARIA GERAL PARLAMENTAR. DEPARTAMENTODEDOCUMENTAÇÃO 
E INFORMAÇÃO. Decreto $n^{\circ}$ 6.537, de 4 de julho de 1934. Cria Cursos Ferroviários. Disponível em: <http: www.al.sp.gov.br/repositório/legislação/decreto/1934/decreto\%20 n.6.537,\%20de\%2004.07.1934.html>. Acesso em: 19 maio 2013.

Decreto $n^{\circ} 14.550$, de 21 de fevereiro de 1945. Dispõe sobre o ensino profissional ferroviário nas estradas de ferro de propriedade e administração do Estado e dá outras providências. Disponível em: < http://www.al.sp.gov.br/repositorio/legislacao/decreto\%20 lei/1945/decreto-lei\%20n.14.550,\%20de\%2021.02.1945.htm>. Acesso em: 15 maio 2013.

Decreto $n^{\circ} 17.698$, de 26 de novembro de 1947. Aprova a Consolidação mandada elaborar pelo Decreto no 17.211, de 13 de maio de 1947. Disponível em: < http:/ /www.al.sp. gov.br/repositorio/legislacao/decreto/1947/decreto\%20n.17.698,\%20de \%2026.11.1947. htm>. Acesso em: 10 jun. 2013.

Decreto $n^{\circ}$ 18.087, de 20 de abril de 1948. Extingue os Núcleos de Ensino Profissional de Bauru e de Pindamonhangaba e o Curso de Ferroviários, anexo à Escola Industrial "Fernando Prestes" de Sorocaba. Disponível em: <http://www.al.sp.gov.br/repositorio/legislacao/ decreto/1948/decreto\%20n.18.087,\%20de\%2020.04.1948.htm>. Acesso em: 30 abr. 2013.

SCHWARTZMAN, S.; BOMENY, H. M. B.; COSTA, V. M. R. N. O ensino industrial. In: SCHWARTZMAN, S.; BOMENY, H. M. B.; COSTA, V. M. R. N. Tempos de Capanema. 2. Ed. Rio de Janeiro: Fundação Getúlio Vargas; Editora Paz e Terra, 2000.

SEGNINI, Liliana Rolfsen Petrilli. Educação, trabalho e desenvolvimento: uma complexa relação. Revista Trabalho e Educação. Belo Horizonte, v. 6, n. 6, p. 15-45, dez./jul. 2000. Disponível em: <http://www.portal.fae.ufmg.br/seer/index.php/trabedu/article/ view/1640/1241>. Acesso em: 20 abr. 2015.

TENCA, Álvaro. Senhores dos trilhos: racionalização, trabalho e tempo livre nas narrativas de exalunos do Curso de Ferroviários da Antiga Paulista. São Paulo: Fundação Editora UNESP, 2006.

WEINSTEIN, Barbara. (Re)Formação da classe trabalhadora no Brasil (1920-1964). São, Paulo: Editora Cortez, 2000.

ZUCCHI, Bianca Barbagallo. A criação da Escola de Ferroviários da Companhia Sorocabana. Revista Histórica. São Paulo, ano 1, n. 4, p. 1-6, 2005. Disponível em: <http://www.historica. arquivodoestado.sp.gov>. Acesso em: março de 2013.

\section{NOTAS}

${ }^{1}$ Projeto financiado pela Fapesp.

${ }^{2}$ A pesquisa documental foi realizada com as edições dos anos de 1940 a 1960 das Revistas Ferroviária e Nossa Estrada. Os exemplares que compõem esse corpus documental fazem parte do acervo de revistas ferroviárias do Museu da Companhia Paulista, em Jundiaí. A base de dados dessas revistas e outros documentos produzidos pelas companhias férreas podem ser acessados em http://www.rosana.unesp.br/\#!/pesquisa/laboratorio-de-patrimonio-cultural/ projetos/projeto-memoria-ferroviaria-pmf/base-de-dados-de-documentacao. Para o período relativo à pesquisa foram encontrados 30 exemplares da Revista Nossa Estrada; quanto à Revista Ferroviária foram encontrados 35 exemplares compreendendo o período 1940-1960.

${ }^{3}$ A partir de 2013, dentro do Projeto Memória Ferroviária, foi criado um Grupo de Trabalho de História Oral visando conhecer a formação e a cultura do trabalho nas ferrovias a partir de relatos de ex-ferroviários da Companhia Paulista e Companhia Mogiana. 
167

Recebido: 10/07/2013

Aprovado: 21/04/2015

Contato:

Sueli Soares dos Santos Batista Rua José Telles, 2081, Condomínio Itaembu

Itatiba $|\mathrm{SP}|$ Brasil

CEP 13.252-741 
